\title{
Respostas internacionais às crises de proteção de pessoas: a responsabilidade de proteger e o surgimento de um novo regime de proteção
}

International Responses to Human Protection Crises: Responsibility to Protect and the Emerging Protection Regime

Réponses internationales aux crises de protection des personnes: la responsabilité de protéger et l'apparition d'un nouveau régime de protection

Alex J. Bellamy

Tradutor: João Paulo Moreira

\section{(2) OpenEdition}

Journals

Edição electrónica

URL: http://journals.openedition.org/rccs/5680

DOI: $10.4000 /$ rccs. 5680

ISSN: 2182-7435

Editora

Centro de Estudos Sociais da Universidade de Coimbra

Edição impressa

Data de publição: 1 Setembro 2014

Paginação: 45-66

ISSN: 0254-1106

\section{Refêrencia eletrónica}

Alex J. Bellamy, « Respostas internacionais às crises de proteção de pessoas: a responsabilidade de proteger e o surgimento de um novo regime de proteção ", Revista Crítica de Ciências Sociais [Online], 104 | 2014, colocado online no dia 23 setembro 2014, criado a 04 maio 2019. URL : http:// journals.openedition.org/rccs/5680 ; DOI : 10.4000/rccs.5680 


\section{Respostas internacionais às crises de proteção de pessoas: a responsabilidade de proteger e o surgimento de um novo regime de proteção}

O presente artigo analisa as discussões contemporâneas travadas no seio do Conselho de Segurança da ONU e outras entidades acerca da proteção de pessoas em resposta a grandes crises humanitárias. A tese que propõe é que existem, naquilo que tem sido a prática do Conselho de Segurança, sinais claros do surgimento de um regime internacional de proteção de pessoas, sugerindo que tal regime assenta no encontro de diversos tipos de entendimento moral sobre o que é a intervenção humanitária. A primeira secção faz a análise de algumas das discussões jurídico-morais suscitadas a propósito das intervenções militares para fins de proteção. A segunda passa brevemente em revista a prática do Conselho de Segurança, fazendo ressaltar o surgimento de uma política de proteção nova. A terceira secção sustenta que, não obstante o uso da força e de outras medidas coercivas continuar a ser controverso, há indícios que apontam no sentido de que o Conselho de Segurança tem vindo a assumir mais seriamente as suas responsabilidades em matéria de proteção, o que configura de maneira consistente o surgimento de um regime de tipo novo.

Palavras-chave: Conselho de Segurança; crise humanitária; intervenção humanitária; Organização das Nações Unidas (ONU); proteção de pessoas.

Em 19 de março de 2011, forças militares da França, do Canadá, do Reino Unido e dos Estados Unidos da América atacaram as defesas antiaéreas e os soldados do regime de Muammar Kadhafi, na Líbia. Estes países encabeçaram uma coligação alargada de Estados com a finalidade expressa de fazer cumprir os objetivos definidos pela Resolução 1973 (de 2011) do Conselho de Segurança das Nações Unidas, concretamente no respeitante ao estabelecimento de uma zona de exclusão aérea sobre a Líbia, à imposição de um embargo de armas e à proteção de civis. No dia seguinte teve lugar em Paris uma cimeira em que se acertaram as modalidades iniciais 
da Operação Amanhecer da Odisseia. Estiveram envolvidos representantes de 18 Estados (sobretudo da Europa e da América do Norte, mas também do Iraque, da Jordânia, de Marrocos, do Qatar e dos Emirados Árabes Unidos), bem como responsáveis da Liga Árabe e da União Europeia. Em 23 de março a direção da NATO passou a estar incumbida da aplicação do embargo de armas; em 26 de março esta organização assumiu a responsabilidade pelo estabelecimento da zona de exclusão aérea, e no dia 31 do mesmo mês chamou a si o controlo absoluto das operações sobre aquilo que passava agora a designar-se Operação Protetor Unificado. Tal participação não incluiu a totalidade dos membros da NATO, ficando de fora, nomeadamente, países como a Polónia e a Alemanha. No entanto a Aliança Atlântica pôde contar com a adesão de outros, como foram os casos da Suécia, Jordânia, Qatar e Emirados Árabes Unidos. A 4 de abril o presidente Barack Obama retirou do combate direto as forças norte-americanas, após o que a parte mais significativa das missões de combate seria travada pela França, Grã-Bretanha, Itália, Dinamarca, Bélgica, o Canadá, os Emirados Árabes Unidos, o Qatar e a Noruega. Graças às operações efetuadas sob o comando da NATO evitou-se a queda do reduto rebelde de Benghazi e o massacre que muitos já previam, e ao cabo de um período em que a linha da frente avançou e recuou com uma rapidez alarmante, o conflito entrou numa fase de impasse. Durante este período a NATO e respetivos aliados prosseguiram no uso da força contra alvos líbios, incluindo instalações de controlo e de comando. Quando, em 19 de agosto, as forças rebeldes leais ao Conselho Nacional de Transição (CNT) invadiram Trípoli, a cidade foi tomada no espaço de uma semana. A luta por redutos governamentais prolongou-se até outubro, altura em que a cidade de Sirte caiu nas mãos das forças rebeldes e em que o próprio Kadhafi acabou por ser capturado e executado.

Como defendi num artigo em coautoria com Paul D. Williams, a resposta dada à crise da Líbia pelo Conselho de Segurança da ONU em 2011 foi significativa por diversos motivos (Bellamy e Williams, 2011), o mais evidente dos quais terá sido o facto de a Resolução 1973 (de 17 de março de 2011) ser a primeira em que o Conselho impôs o uso da força militar contra as autoridades legítimas de um Estado-Membro da ONU com a finalidade de proteger pessoas. Embora já antes tivesse estado perto de o fazer, a verdade é que nunca o Conselho tinha atravessado essa linha. Com efeito, na Resolução 794 (de dezembro de 1992) o Conselho autorizara a Força de Intervenção Unificada a entrar na Somália para aliviar a crise humanitária, mas isso foi em contexto de ausência de governo e não propriamente contra um governo. Do mesmo modo, através da 
Resolução 929 (de junho de 1994) o Conselho de Segurança deu autorização para a Operação Turquesa, sob comando da França, com o ostensivo propósito humanitário de proteger as vítimas do genocídio então em curso no Ruanda. Apesar de uma certa preocupação generalizada quanto às motivações do Governo francês, a Operação Turquesa contou com o consentimento do Governo provisório do Ruanda e das suas Forças Armadas. Por meio da Resolução 940 (de setembro de 1994), o Conselho de Segurança autorizou o uso da força militar para derrubar a junta haitiana. Mas esta missão não só teve o explícito apoio das autoridades legítimas do Haiti (S/1994/905, anexo) como assentou a sua justificação primacialmente na referência à defesa da democracia, de tal modo que a proteção dos civis haitianos foi deixada apenas implícita nas alusões feitas pela Resolução à necessidade de a força de intervenção manter um "ambiente seguro e estável” (parágrafos dispositivos 4 e 9-A). Mais recentemente, o Conselho de Segurança autorizou o uso de todas as medidas necessárias à proteção de civis na República Democrática do Congo, no Sudão, no Sudão do Sul e na Costa do Marfim, porém as operações dos capacetes azuis nestes países ocorreram, na sua totalidade, com a permissão oficial das respetivas autoridades legítimas. Não foi esse o caso da Líbia, onde o Conselho de Segurança pisaria, pela primeira vez, terrenos políticos novos: o uso da força contra um governo legítimo, com o objetivo declarado de proteger civis.

Igualmente significativa foi a disposição do Conselho de aplicar rapidamente um pacote de medidas que apenas excluíam o uso da força militar, com vista a coagir as autoridades líbias e persuadi-las a mudar de rumo. A Resolução 1970 (de 26 de fevereiro de 2011) veio impor sanções financeiras especificamente dirigidas, obrigar a um embargo de armas, remeter a situação para o Tribunal Penal Internacional, ordenar a intensificação da via diplomática, e exigir uma solução pacífica para o conflito. De facto, uma avaliação recente sugere que, com a Resolução 1970, o Conselho quase esgotou o seu "estojo preventivo", ficando a um passo de autorizar o uso da força militar (Reike, 2012).

Finalmente, devido à circunstância de o Conselho se referir ao princípio da "responsabilidade de proteger" (RdeP) em quatro das suas resoluções sobre a Líbia - 1970 (2011), 1973 (2011), 2016 (2012) e 2040 (2012) -, não admira que a resposta à situação no país tenha sido caraterizada como sendo um teste crucial. Para alguns dos defensores deste princípio, como Gareth Evans (2012: 1), as resoluções 1970 e 1973 constituíram "um exemplo antológico de como a Responsabilidade de Proteger deverá funcionar em situação de atrocidades em massa com um evoluir rápido”. 
Contudo, a aplicação da Resolução 1973 não deixou de estar rodeada de controvérsia, decorrente da opinião muito generalizada segundo a qual as ações da NATO e seus aliados teriam ultrapassado - ou teriam mesmo chegado a violar - os termos da Resolução 1973. A este respeito, terão sido fundamentais: o esforço ostensivo por parte da coligação no sentido de provocar a mudança de regime, ainda que sem mandato específico para tal; o fornecimento de armas a grupos rebeldes, potencialmente em violação do embargo ditado pelo Conselho; e a falta de abertura da NATO para chegar a um acordo negociado, não obstante ele estar explicitamente previsto na Resolução. Estas preocupações suscitaram críticas significativas por parte de membros do Conselho, incluindo dois membros permanentes (China e Rússia) e várias potências emergentes de vulto (nomeadamente o Brasil, a Índia e a África do Sul). Tais preocupações também deram origem, entre outros aspetos, à elaboração, pelo Brasil, do conceito de "responsabilidade ao proteger", o qual abarca um apelo à limitação da tomada de decisões por parte do Conselho (através da ênfase na prevenção e de critérios para a condução das tomadas de decisão) e as medidas de responsabilização no processo de supervisionamento da aplicação das suas próprias resoluções. A intervenção na Líbia veio ainda reacender desconfianças latentes quanto ao potencial do princípio da RdeP para se prestar a abusos por parte de países ocidentais apostados em "mudanças de regime". Como resultado, em certa medida, de tudo isto, ter-se-á gerado no seio do Conselho, segundo alguns analistas, um clima impeditivo da busca de um espaço de entendimento comum em crises subsequentes, com evidência para o caso da Síria. Assim, alguns comentadores defendem que a incapacidade do Conselho para chegar a consenso sobre a Síria configura, efetivamente, uma situação de "danos colaterais" decorrentes da forma como o Conselho geriu o caso da Líbia (Goldberg, 2012).

O presente artigo analisa as discussões contemporâneas travadas no seio do Conselho de Segurança da ONU e outras entidades acerca da proteção de pessoas em resposta a grandes crises humanitárias, defendendo a tese de que, não obstante a controvérsia gerada com a situação da Líbia e os problemas decorrentes da resposta dada pela comunidade internacional à crise na Síria, existem sinais claros do surgimento de um regime internacional de proteção. $\mathrm{O}$ artigo desenvolve-se em três partes. A primeira secção faz a análise de algumas das discussões jurídico-morais suscitadas a propósito das intervenções militares para fins de proteção. A segunda passa brevemente em revista a prática do Conselho de Segurança, fazendo ressaltar o surgimento de uma política de proteção 
nova. A terceira secção sustenta que, não obstante o uso da força e de outras medidas coercivas continuar a ser controverso, há indícios que apontam no sentido de que o Conselho de Segurança tem vindo a assumir mais seriamente as suas responsabilidades em matéria de proteção, porquanto é hoje maior a probabilidade de se envolver em crises em que esteja em causa proteger.

\section{A intervenção em debate}

Historicamente, os genocídios e os episódios de morticínio costumam terminar numa de duas maneiras: ou os seus responsáveis conseguem alcançar aquilo que ambicionam, ou são impedidos pela força (Bellamy, 2009; de Waal e Zilkic, 2006). Este simples facto é confirmado por exemplos recentes. O genocídio de 1994 no Ruanda terminou com a derrota do governo do país e da milícia interehamwe às mãos de um grupo rebelde denominado Frente Patriótica Ruandesa (PFR); a guerra da Bósnia chegou ao fim quando o equilíbrio militar se desfez em favor de uma coligação croata-muçulmana apoiada pelo poderio aéreo da NATO; e foi também esse poderio aéreo que pôs fim à limpeza étnica no Kosovo. Por outro lado, o índice de mortandade no Darfur diminuiu após ter atingido um máximo em 2003/2004, principalmente porque a milícia Janjaweed e aqueles que a apoiavam dentro do governo obrigaram, em grande medida, os seus inimigos a ir para o exílio, enquanto na Síria o fracasso de ambas as partes em alcançar uma vitória decisiva conduziu a um conflito prolongado e marcado por atrocidades em massa.

Factos como este colocam um enorme desafio à paz e segurança internacionais. Tradicionalmente a segurança sempre foi vista, e tanto pelos liberais como pelos realistas, como atribuição dos Estados, sendo os princípios da soberania e da não interferência dois dos principais garantes da segurança nacional. ${ }^{1}$ Segundo esta perspetiva, a melhor forma de atingir a segurança internacional será através de uma sociedade de Estados soberanos com jurisdição exclusiva sobre uma determinada porção de território e o direito à não interferência e não intervenção consagrado na Carta da Organização das Nações Unidas (Bull, 1977). A isto se chama com frequência "a soberania de Vestefália", numa alusão à Paz de Vestefália de 1648, que comummente se considera haver instituído uma ordem mundial baseada no direito dos soberanos à jurisdição sobre o seu próprio território e na visão segundo a qual as leis internacionais se devem limitar a reger a convivência entre os Estados, não se envolvendo

${ }_{1}^{1}$ Para uma boa explanação desta visão, ver Jackson (2000). 
nos respetivos assuntos internos. ${ }^{2}$ As regras que, na comunidade internacional contemporânea, ditam as relações entre os Estados contêm no seu cerne alguns aspetos desta ideia. O Artigo 2. (4) da Carta da ONU proíbe a ameaça ou o uso da força por parte dos Estados no relacionamento entre si, e o Artigo 2. ${ }^{\circ}$ (7) proíbe a ONU de se imiscuir nos assuntos internos dos respetivos Estados-Membros. Há apenas duas exceções à proibição do uso da força constante do Artigo 2. ${ }^{\circ}$ (4): o Artigo 39. ${ }^{\circ}$, que confere ao Conselho de Segurança da ONU o direito a autorizar ações militares nos casos em que esta detete uma "ameaça à paz e à segurança internacionais", e o Artigo 51. ${ }^{\circ}$, que reconhece a todos os Estados o inerente direito de legítima defesa.

A valia do sistema vestefaliano de segurança assenta no pressuposto de que os Estados são os melhores guardiões da segurança dos seus cidadãos e refletem os valores e preferências morais das comunidades que albergam (ver por exemplo Walzer, 1994). Dito de outro modo, a segurança do Estado é considerada importante e merecedora de proteção porque os Estados oferecem segurança aos indivíduos, permitindo que as comunidades prosperem nas condições que elas mesmas ditem. Dos parágrafos acima deve resultar claro, no entanto, que este pressuposto tem o seu quê de problemático. No século passado as ameaças à segurança das pessoas tenderam a provir mais do Estado a que estas pertenciam do que de outros Estados (Commission on Human Security, 2003: 2). Tal facto levanta a questão de saber se haverá circunstâncias em que a segurança das pessoas deve prevalecer sobre a segurança dos Estados.

Consequentemente, a discussão sobre o uso da força para fins de proteção prende-se com a questão de saber se o direito dos Estados a manterem-se seguros e livres de interferências externas deve subordinar-se ao cumprimento de certas responsabilidades para com os respetivos cidadãos, entre as quais não é despicienda a responsabilidade de proteção contra o morticínio. Propõe-se assim, como instrumento heurístico, a representação dos diferentes posicionamentos ao longo de dois eixos, o primeiro correspondendo à nossa conceção daquilo que é possível em política mundial, o segundo referente a quais os atores a privilegiar (ver a Tabela 1).

O primeiro eixo da Tabela 1 corresponde ao modo como percecionamos o potencial e os limites da política mundial. Algumas teorias da ética internacional fundam-se numa visão intrinsecamente otimista segundo

${ }^{2}$ Para uma reflexão sobre as conceções vestefalianas e pós-vestefalianas de soberania, ver Bellamy e Williams (2010). 
a qual, dado o diálogo entre comunidades diversas ser viável, e ser por isso possível também o consenso moral e a prossecução de objetivos comuns, é igualmente possível haver progresso humano. Em resultado deste facto, o diálogo tem a capacidade de promover conceções comuns do bem, e a ação coletiva empreendida com determinação e sentido ético consegue impelir a humanidade de forma positiva nessa direção. A visão kantiana de uma paz perpétua construída passo a passo através da regulamentação da guerra e, subsequentemente, da criação de uma comunidade de nações constitui um bom exemplo do que é uma conceção otimista (Kant, 1903 [1795]).

O contraponto disto será uma conceção essencialmente fatalista ou "trágica" da política mundial. Tal perspetiva baseia-se na visão segundo a qual o mundo é constituído por unidades culturalmente distintas, cada uma com os seus valores e objetivos próprios e diversos, e com uma margem de cooperação limitada (ver por exemplo Niebuhr, 1938; Morgenthau, 1948; e ainda Lebow, 2003). Procurar impor aos outros as crenças próprias só pode gerar resistência, produzindo muitas vezes resultados trágicos que deixam todas as partes pior do que estavam antes. Esta visão encara com ceticismo a possibilidade de progresso, duvida que a moral possa (ou deva) ter lugar nos assuntos mundiais, e preconiza que os eventuais esforços para difundir valores morais acabarão por custar caro e revelar-se contraproducentes. Em suma, a conceção trágica aponta no sentido de que "seria errado considerar que, se os indivíduos agissem de forma ética, a condição humana conheceria progressos ou melhorias" (Frost, 2003: 484).

O segundo eixo da Tabela 1 tem a ver com uma questão ontológica, que é a de saber que tipo de ator privilegiar. No caso vertente, fixemo-nos na questão de saber se se deve privilegiar os Estados ou as pessoas. As teorias das Relações Internacionais costumam privilegiar o Estado pelo facto de este ser o principal ator da cena mundial, a fonte primordial da ordem, e o guardião dos direitos e responsabilidades internacionais. Esta perspetiva transmite também a ideia de que as comunidades, ou nações, possuem um valor intrínseco. As nações desfrutam de uma cultura e de toda uma "vida em comum", pelo que deverão dispor da liberdade de determinar as suas próprias formas de governo. Segundo os comunitaristas, existe como que um "encaixe" perfeito entre a comunidade política e o Estado, com este último a criar condições para que aquela desenvolva e proteja os seus próprios valores e ideias acerca da maneira como os respetivos membros hão de viver (Walzer, 1977: 87; 1994). De acordo com Walzer (1983: 312-313), “a justiça varia consoante os 
significados sociais: existe um número infinito de vidas possíveis, por sua vez moldadas por um número infinito de possíveis culturas, religiões, disposições políticas, circunstâncias geográficas, etc. Uma sociedade será justa se a sua vida substantiva for vivida de uma determinada maneira - quer dizer, de uma maneira fiel àquilo que é o entendimento comum dos respetivos membros”. Já uma perspetiva alternativa privilegiará a pessoa enquanto única entidade ontológica irredutível. Deste ponto de vista, há que entender a instância Estado e a soberania que é seu apanágio como valores instrumentais - e não como fins em si mesmos -, uma vez que o seu valor moral decorre da capacidade que o Estado tem para salvaguardar o bem-estar dos cidadãos. Afinal de contas, foram os seres humanos que inventaram os Estados para cumprir determinados objetivos, não o inverso. Quando falham com a sua obrigação, os Estados perdem os seus direitos soberanos (Tesón, 2003: 93). São diversos os modos de se chegar a esta conclusão. Alguns pensadores partem do conceito kantiano de ser racional para acentuar a ideia de que todos os indivíduos são detentores de certos direitos pré-políticos (Caney, 2005: 34). Outros citam a defesa insistente que Santo Agostinho faz do recurso à força como forma de defender a ordem pública, para argumentar que a intervenção destinada a travar a injustiça estaria "entre os direitos e deveres dos Estados enquanto não - e a menos que - suplantados por uma instância de governo superior" (Ramsey, 2002: 20,35-36). Por outro lado, a experiência histórica mostra que, quer na teoria quer na prática, os direitos soberanos andaram sempre associados a responsabilidades de um ou outro tipo (Glanville, 2011).

TABELA 1 - Valores e perspetivas em confronto

\begin{tabular}{lll}
\hline & \multicolumn{1}{c}{ centrada no Estado } & \multicolumn{1}{c}{ centrada na pessoa } \\
\hline \multirow{4}{*}{ trágica } & realista & pós-estruturalista \\
& pós-colonial (?) & feminista (crítica) \\
& marxista & pós-colonial (?) \\
& comunitarista (?) & humanitária clássica \\
\hline \multirow{4}{*}{ otimista } & utilitarista em função da norma & internacionalista liberal \\
& legal-positivista & contratualista social \\
& pluralista (escola inglesa) & cosmopolita \\
& comunitarista (?) & solidária (escola inglesa) \\
& & lei natural \\
\hline
\end{tabular}


Como se pode ver pela Tabela, e tendo sempre em mente que estamos perante um mero exercício heurístico, equacionar o posicionamento ético sobre a intervenção humanitária em função destes dois eixos dá-nos quatro grandes configurações: otimista/centrada no Estado, trágica/ /centrada no Estado, otimista/centrada na pessoa, e trágica/centrada na pessoa. Estas quatro configurações proporcionam entendimentos diversos em resposta à questão de saber se por vezes a soberania não deverá ser posta de parte em nome dos direitos humanos, formas diversas de avaliar intervenções concretas, e modos também diversos de responder adequadamente ao problema dos massacres e do sofrimento humano.

Os últimos anos assistiram a significativos progressos práticos no sentido da superação de alguns dos conflitos morais que resultam destas questões. Destes destaca-se o princípio da RdeP. Adotado em 2005 por mais de 150 dirigentes de todo o mundo e reafirmado pelo Conselho de Segurança da ONU no ano seguinte através da Resolução 1674 e, posteriormente, das Resoluções 1894 (2009) e 2150 (2014), ele veio procurar reconciliar duas preocupações que andam a par - a soberania dos Estados e a segurança das pessoas -, estipulando as responsabilidades dos Estados para com as respetivas populações e a responsabilidade da comunidade internacional nos casos em que os Estados não cumprem com as suas obrigações ou experimentam dificuldades em fazê-lo. Situando as possibilidades de intervenção humanitária ao longo de um amplo espetro de medidas, como o alerta precoce e o desenvolvimento de capacidades destinadas a evitar que as crises cheguem a eclodir, a RdeP trouxe consigo igualmente a promessa de fazer frente a alguns dos problemas práticos associados à intervenção humanitária. ${ }^{3}$ Ao enquadrar toda esta ideia nas normas de coexistência fixadas pela Carta das Nações Unidas, os adeptos da RdeP procuravam encontrar terreno comum com os defensores de uma visão mais trágica, ou estadocêntrica, das condições da política mundial. Esse terreno comum era já, afinal, reflexo da prática emergente do Conselho de Segurança da ONU, como se demonstra na secção a seguir.

\section{Rumo a uma "nova" Política de Proteção?}

Conforme ficou dito atrás, a RdeP foi aprovada por unanimidade pelos Estados-Membros da ONU na Cimeira Mundial de 2005. Esta reconheceu que os Estados têm a responsabilidade de proteger as suas populações contra o genocídio, os crimes de guerra, a limpeza étnica e os crimes contra a humanidade; que é dever da comunidade internacional ajudar

${ }_{3}^{3}$ Sobre o surgimento do princípio da responsabilidade de proteger, ver Evans (2010). 
os Estados a dar cumprimento às suas responsabilidades em termos de proteção; e que, caso um Estado se revele "manifestamente incapaz" de proteger as populações contra estes crimes, caberá à comunidade internacional tomar medidas "tempestivas e decisivas" com base nas várias disposições previstas na Carta das Nações Unidas. Desde então, a RdeP foi sucessivamente reafirmada nas resoluções do Conselho - incluindo as Resoluções 1674 (2006), 1894 (2009) e 2150 (2014) -, nos relatórios do Secretário-Geral, e aquando da criação de um gabinete conjunto para a RdeP e a prevenção de genocídio. Além disso, a RdeP também mereceu lugar de destaque na resposta do Conselho de Segurança às crises relacionadas com o problema da proteção na Costa do Marfim, na Líbia, no Mali, no Iémen, na República Centro-Africana e no Sudão do Sul. O princípio foi, inclusivamente, referido pelo Conselho num comunicado de imprensa sobre a situação na Síria.

Embora a adoção formal e a subsequente utilização da RdeP tenham constituído um marco indubitavelmente importante no contexto do continuado envolvimento da comunidade internacional no problema de genocídio e das atrocidades em massa, já desde os finais da década de 1990 que o Conselho de Segurança se vinha ocupando das questões da proteção de pessoas, tendo desenvolvido uma agenda temática para a proteção de civis relacionada com a RdeP, mas diferente desta. Tal facto mostra que RdeP se insere numa tendência mais vasta no sentido da criação de um regime internacional de proteção de pessoas (Bellamy e Williams, 2011). Assim, e mais concretamente, no trabalho desenvolvido pelo Conselho no âmbito da proteção de civis em conflitos armados encontram-se abrangidas exigências de conformidade com o direito internacional humanitário, aspetos operacionais relacionados com as operações de paz e com o acesso à ajuda humanitária, o papel do Conselho na resposta a situações de emergência e ainda questões de desarmamento.

Em 1999 foi aprovada por unanimidade a Resolução 1265, através da qual o Conselho mostrava "abertura" a "medidas apropriadas" de resposta a situações de conflito armado em que os civis fossem alvo ou em que a ajuda humanitária a civis estivesse a ser deliberadamente obstruída; apelava aos Estados no sentido de ratificarem tratados fundamentais em matéria de direitos humanos e trabalharem com vista a pôr fim à "cultura de impunidade", movendo processos contra os responsáveis por casos de genocídio, crimes contra a humanidade e "violações graves do direito internacional humanitário"; e manifestava a sua abertura para estudar maneiras de os mandatos de manutenção da paz serem reformulados com vista a proporcionar melhor proteção a civis ameaçados. 
Em 2004 o Conselho produziu um memorando sobre proteção civil, posteriormente adotado e trabalhado pelo Gabinete de Coordenação dos Assuntos Humanitários das Nações Unidas (OCHA). Em abril de 2006 o Conselho emitiu nova Resolução (1674) sobre a proteção de civis, que veio reafirmar a RdeP, reiterar as exigências do Conselho em matéria de acesso humanitário em zonas de crise, e manifestar a prontidão para atuar nas situações em que civis fossem deliberadamente tomados como alvo. No ano seguinte o Secretário-Geral, Ban Ki-moon, criou um grupo de trabalho para estudar formas de traduzir em resultados palpáveis para as populações ameaçadas o compromisso do Conselho com a proteção. Mais recentemente, já em finais de 2013, o Secretariado das Nações Unidas adotou uma nova estratégia de resposta às crises de proteção de pessoas. Designada "Os Direitos Primeiro", a nova estratégia determina que as situações em que os direitos humanos se afigurem passíveis de evoluir para crimes de atrocidades em massa sejam monitorizadas por funcionários das Nações Unidas, aos quais caberá igualmente prestar informações sobre tais situações, trazê-las perante o Conselho de Segurança, e elaborar respostas coordenadas para lhes fazer frente.

$\mathrm{O}$ apoio do Conselho à proteção de pessoas traduziu-se também na formulação de mandatos relevantes para as operações de paz. A proteção passa agora, assim, a ser largamente encarada como uma das funções principais das operações de paz e essencial para a legitimidade destas. Não obstante algumas das primeiras operações de manutenção da paz conterem uma componente de direitos humanos, só muito raramente a proteção de civis era considerada um objetivo central da missão. A partir de 1999, ano da missão das Nações Unidas na Serra Leoa (UNAMSIL), o Conselho de Segurança passou a invocar com regularidade o Capítulo VII da Carta da ONU para criar mandatos de proteção. Pouco depois, o Relatório Brahimi veio defender que às forças de paz que testemunhem violência contra civis deverá ser oficialmente "concedida autorização tácita para lhe pôr fim, na medida dos meios ao seu alcance". Desde então, as operações de paz no Haiti (MINUSTAH), no Burundi (ONUB), na Libéria (UNMIL), no Sudão (UNMIS, UNAMID), na República Democrática do Congo (MONUC//MONUSCO), no Mali (Misca), na República Centro-Africana (MINUSMA) e no Sudão do Sul (UNMISS), bem como a UNOCI, na Costa do Marfim, contaram, ao abrigo do Capítulo VII, com mandatos que permitiam o uso de "todos os meios necessários" para a proteção de civis, ainda que geralmente com a introdução de uma ou outra importante ressalva relacionada com as circunstâncias geográficas, temporais e de capacidades. A utilização 
habitual do Capítulo VII em mandatos de operações de paz destinados a proteger civis constituiu uma evolução importante no pensamento do Conselho. Deve salientar-se, no entanto, que todas essas missões foram levadas a cabo com o consentimento - ainda que por vezes mediante coação e duvidosa fiabilidade - dos governos reconhecidos como legítimos. Com efeito, para pelo menos um dos membros permanentes do Conselho de Segurança - a China - o consentimento do Estado anfitrião deveria ser condição necessária em todos os destacamentos deste tipo (ver Teitt, 2011). Na prática, as ressalvas e os problemas associados ao consentimento tiveram como consequência que as operações de paz recorreram com pouca frequência à força para proteger civis, e na maioria das vezes apenas contra atores não estatais (apesar de a culpa estar, muitas vezes, do lado das forças governamentais).

No seu esforço de proteger civis, o Conselho de Segurança utilizou também, ao longo da última década, a via da delegação de autoridade em acordos regionais. Foi assim nas operações que as forças francesas chefiaram no Mali em 2012 e na República Centro-Africana em 2013, e na Missão da União Africana na Somália (AMISOM). A exemplo das missões da ONU, estas operações gozaram de autorização para recorrer à força, contando com o consentimento nominal das autoridades legítimas dos países em causa.

Há que ver as discussões sobre o uso da força para fins de proteção e a resposta do Conselho de Segurança à crise na Líbia no contexto destas alterações ocorridas no âmbito da política de proteção. Há que atentar, especialmente, na crescente abertura do Conselho de Segurança para autorizar o recurso, em operações de paz levadas a cabo por coligações ou pelos "capacetes azuis", a todos os meios necessários - incluindo o uso da força - para fins de proteção de pessoas. Esta tendência acabaria por se consolidar no contexto da discussão internacional sobre a RdeP e da própria disposição do Conselho para reafirmar o princípio. Colocavam-se, contudo, limites claros para aquilo que o Conselho e, de um modo geral, a comunidade internacional se dispunham a fazer. Em particular, até ao caso da Líbia o Conselho mostrou relutância em autorizar o uso da força contra Estados. Esta intervenção deu naturalmente origem a críticas contundentes por parte de Estados como a Rússia, a China, a África do Sul e a Índia, que sustentaram que a NATO e seus aliados terão excedido o mandato limitado que haviam recebido para proteger civis ao enveredarem por uma óbvia agenda de mudança de regime. Como já referi, muitos analistas vêm defendendo que a controvérsia gerada em torno da Líbia travou o consenso emergente sobre a proteção de 
pessoas descrito na presente secção, acabando por inibir uma ação concertada de resposta à crise na Síria. A secção que se segue faz uma avaliação dessa tese através de uma apreciação breve do que foi o comportamento global da comunidade internacional desde os acontecimentos da Líbia. A ideia para que se aponta é que, embora o caso da Líbia se tenha revelado assaz controverso e a comunidade internacional tenha sido incapaz de responder com eficácia à crise na Síria, abundam os indícios de que, no fundo, se estão a verificar avanços em direção a um regime de proteção de pessoas.

\section{A responsabilidade de proteger e o Conselho de Segurança da ONU após a Líbia}

Em que medida é que o facto de o Conselho não ter respondido com eficácia à crise da Síria foi reflexo de tendências mais generalizadas presentes nos organismos políticos da ONU a seguir à situação na Líbia? A ser verdade que o caso da Líbia terá afetado negativamente o consenso global em matéria de RdeP e proteção de pessoas, seria de esperar encontrar-se provas disso nas respostas mundiais às crises de proteção ocorridas desde a Resolução 1973. No entanto, e como se irá demonstrar na presente secção, são escassas as indicações de que o Conselho de Segurança ou a Assembleia-Geral da ONU tenham passado a usar de maiores cautelas no seu recurso à RdeP ou na assunção da responsabilidade de proteção - o que não significa, obviamente, que estas instituições tenham logrado reagir com eficácia na totalidade das situações. Uma coisa é aceitar e concordar com um princípio, outra coisa completamente diferente será chegar a acordo quanto à melhor maneira de dar cumprimento a esse princípio em situações reais difíceis e perigosas. O que aqui está em causa, porém, é saber até que ponto terá havido, desde meados de 2011, um abrandamento a nível internacional das atitudes para com a RdeP e o regime emergente de proteção de pessoas. A presente secção começa por se debruçar sobre o Conselho de Segurança, detendo-se de seguida sobre a Assembleia-Geral.

Em setembro de 2005 a Assembleia-Geral da ONU adotou o princípio da RdeP. Nos 65 meses decorridos desde então até à primeira resolução do Conselho de Segurança sobre a Líbia (Resolução 1970, de 26 de fevereiro de 2011), o Conselho fez referência àquele princípio por apenas quatro vezes. Destas, apenas duas tiveram a ver com situações específicas, já que em duas ocasiões o Conselho se limitou a reafirmar a RdeP em resoluções temáticas sobre a Proteção de Civis em Conflitos Armados (Resolução 1674, de 2006; e Resolução 1894, de 2009). Das outras duas, uma versou 
genericamente a situação regional na zona africana dos Grandes Lagos, concretamente a propósito do Burundi e da República Democrática do Congo. Esta Resolução "sublinhou” a ideia de que competia aos Estados da região a principal responsabilidade de proteger as suas populações, exortando-os a promover os direitos humanos e a boa governação, bem como a negar refúgio aos grupos armados estranhos ao Estado. Produzida apenas alguns meses mais tarde, a Resolução 1706, respeitante à situação no Darfur, "lembrou" as disposições da Cimeira Mundial em matéria de RdeP e autorizou o envio para o Darfur de alguns elementos da Missão da ONU no Sudão (UNMIS). A inclusão, nesta Resolução, do princípio da RdeP revelar-se-ia de tal forma polémica que os termos da formulação foram deixados de fora de resoluções subsequentes sobre o Darfur, não constando também das resoluções do Conselho sobre a Somália (mormente a Resolução 1814, de 2008), não obstante os apelos, entre outros, do Representante Especial do Secretário-Geral das Nações Unidas sobre a questão (Strauss, 2009: 57).

Só passados quase 5 anos o Conselho voltaria a aludir à RdeP em relação à situação concreta de um país. Durante esse período abriram-se e (de alguma forma também) encerraram-se grandes crises de proteção no Sri Lanka, na Guiné, no Quénia, no Leste da República Democrática do Congo, no Quirguistão, na Somália, no Darfur e no Sudão e Sudão do Sul. Em 2009, Ekkehard Strauss (2009: 58) fazia o ponto da situação no Conselho de Segurança ao escrever: "devido à desunião, se não mesmo à oposição, de alguns dos seus Estados-Membros, o Conselho viu-se até agora impedido de aplicar a responsabilidade de proteger em situações específicas de crise nacional".

A ser verdadeiro que os juízos negativos emitidos acerca da intervenção da NATO na Líbia teriam prejudicado o consenso internacional quanto à $\mathrm{RdeP}$ e ao regime emergente de proteção de pessoas e que teriam sido utilizados pelos seus detratores com vista a deslegitimá-la, seria de esperar, entre outras coisas, que a aversão do Conselho de Segurança por aquele princípio, evidenciada desde meados de 2006 até ao início de 2011, conhecesse um ressurgimento no período pós-Líbia. O facto, porém, é que se deu precisamente o oposto. Não obstante as recriminações a propósito da aplicação da Resolução 1973 sobre a Líbia, o Conselho de Segurança mostrou maior abertura ao recurso à RdeP em situações específicas do que antes do caso da Líbia. Se, no período de 65 meses imediatamente anterior à Resolução 1973 sobre a Líbia, o Conselho havia produzido quatro resoluções com alusões à RdeP, à data da escrita deste ensaio esse número ascendia a 10 num período 
de 33 meses, a que acrescem três declarações da Presidência, incluindo uma sobre a Síria. Ou seja, o Conselho não só não virou costas a uma eventualmente deslegitimada RdeP como terá passado, após a Líbia, a abraçar este princípio como nunca antes o fizera.

Entre as resoluções sobre a RdeP contam-se novas resoluções sobre a Líbia em que ficou sublinhada a primordial responsabilidade de proteger por parte do Governo líbio (Resolução 2014, de 2011; e Resolução 2040, de 2012), o que leva a crer que a polémica em torno da intervenção da NATO naquele país não só não deslegitimou, em sentido genérico, o princípio da RdeP, como nem sequer inibiu o Conselho de utilizar estas formulações com referência à situação líbia. Acresce que, desde meados de 2011, o Conselho se referiu à RdeP com relação à situação de 5 países: Costa do Marfim (Resolução 1975, de 2011), Sudão do Sul (Resolução 1996, de 2011), Iémen (Resolução 2014, de 2011), Mali (Resolução 2085, de 2012) e República Centro-Africana (Resolução 2121, de 2013). O Conselho mencionou ainda a RdeP na Declaração da Presidência sobre diplomacia preventiva, em 2011 (S/PRST/2011/18, de 22 de setembro), na Declaração de 2013 sobre a Paz e Segurança em África (S/PRST/2013/4, de 15 de abril), e na Declaração sobre a Síria (S/PRST 2013/15, de 2 de outubro de 2013). A Declaração do Conselho sobre a paz e a segurança em África foi especialmente efusiva na expressão do comprometimento do Conselho com a RdeP e do apoio do Secretário-Geral nesta matéria.

Para além do facto de ter passado a referir formalmente a RdeP com muito maior frequência a partir do caso da Líbia, a inclusão deste princípio nas resoluções e declarações passou também a ser significativamente menos controversa do que aquando da Resolução 1706. Com efeito, nas 10 resoluções acima mencionadas a inclusão da RdeP foi bastante incontroversa. Vários funcionários e diplomatas da ONU envolvidos na atividade do Conselho de Segurança fizeram eco deste ponto de vista em privado, havendo também testemunhos públicos que apontam no mesmo sentido. A Resolução 1975 (de 30 de março de 2011), sobre a Costa do Marfim, passou com unanimidade. Aprovada ao abrigo do Capítulo VII da Carta das Nações Unidas, esta Resolução veio reafirmar a responsabilidade primordial de cada Estado de proteger as populações civis, ao mesmo tempo que autorizava um reforço da missão da ONU naquele país (UNOCI) por forma a consignar o uso de "todos os meios necessários" para a proteção de civis. Nas declarações que os membros do Conselho produziram sobre a Resolução, nenhum aludiu à RdeP, o que parece indicar que a sua inclusão não gerou controvérsia (S/PV.6508, de 30 de 
março de 2011). Igualmente aprovada por unanimidade foi a Resolução 1996 (2011), sobre o Sudão do Sul. Adotada, mais uma vez, ao abrigo do Capítulo VII da Carta, esta Resolução criou uma missão da ONU para o Sudão do Sul (UNMISS), com um mandato destinado, entre outras coisas, a aconselhar e apoiar o governo no tocante à "sua responsabilidade de proteger as populações civis”. A Resolução foi adotada sem que houvesse declarações por parte dos membros do Conselho, o que, uma vez mais, parece sugerir ter sido pacífica a inclusão da RdeP (S/PV.6576, de 8 de julho de 2011). A exemplo destas, também a Resolução 2014, sobre o Iémen, foi adotada por unanimidade e sem declarações (S/PV.6634, de 21 de outubro de 2011). Nesta Resolução o Conselho recordou ao Governo iemenita a sua responsabilidade primeira em termos de proteção das populações. Sob a égide do Capítulo VII, a Resolução 2085 (de 2012) veio autorizar a criação, no Mali, de uma Missão Internacional de Apoio (AFISMA), destinada, entre outros objetivos, a "ajudar as autoridades malianas na sua responsabilidade primária de proteção às populações”. A Resolução mereceu aprovação unânime, não tendo a inclusão da RdeP suscitado qualquer referência nas declarações formais dos membros do Conselho (S/PV.6898, de 20 de dezembro de 2012). Finalmente, nas duas novas resoluções sobre a Líbia (Resolução 2016, de 2011; e Resolução 2040, de 2012) ficou realçada a responsabilidade fundamental do governo no respeitante à proteção das populações, com uma especial chamada de atenção para a proteção dos cidadãos estrangeiros e dos imigrantes africanos. Ambas foram adotadas por unanimidade e sem declarações formais.

É, por fim, de notar que, quando, na Síria, as condições no terreno se alteraram, em agosto de 2013, a posição do Conselho de Segurança da ONU também se modificou. O ataque com armas químicas em Ghouta, cujo número de vítimas civis poderá ter atingido o milhar, acabaria por condicionar o Conselho, forçando-o, primeiro, a exigir uma investigação independente pela ONU, e em seguida, quando a investigação tornou patente a responsabilidade do regime, a dar passos com vista à eliminação das armas químicas no país. Simultaneamente, o Conselho começou também a exigir o cumprimento do direito internacional humanitário e acesso para fins humanitários, lembrando ao Governo sírio a responsabilidade de proteger. Tudo isto vai no sentido de sugerir que, quando confrontados com provas evidentes de que uma das partes é culpada de crimes de guerra ou contra a humanidade passíveis de invalidar os apelos a um tratamento imparcial ou "equidistante", Estados como a Rússia e a China veem-se impossibilitados de legitimar um eventual veto. Este facto, por sua vez, reforça a ideia de que os fatores que estiveram associados 
à questão da Síria tiveram um papel mais relevante na determinação da resposta internacional do que o conjunto de preocupações de natureza mais geral sobre as normas internacionais que caraterizou a experiência da Líbia.

A partir deste retrato sucinto da prática do Conselho de Segurança, são escassos os indícios para sustentar a ideia de que o processo da Líbia teria levado o Conselho a uma menor abertura quanto à incorporação da RdeP nas suas fórmulas e prática efetiva. Assim, vemos não só que o Conselho passou, desde a Resolução 1973, a referir a RdeP em resoluções substantivas muito mais frequentemente do que o fizera antes, mas também que a inclusão, nas resoluções, do discurso da responsabilidade de proteger passou a ser muito menos controversa. Mais do que isso ainda, com a alteração da situação na Síria mudou igualmente a resposta do Conselho, do que resultou uma nova iniciativa com vista à eliminação das armas químicas e o próprio recurso direto à RdeP.

Prova adicional de que a incapacidade do Conselho de Segurança para chegar a consenso com vista a uma ação tempestiva e decisiva na Síria não foi consequência de uma reação política negativa de contornos mais vastos contra a $\mathrm{RdeP}$ e, mais genericamente, a proteção de pessoas, é que muitas das medidas propostas para a Síria que colheram o veto da Rússia e da China no Conselho de Segurança acabaram por merecer o apoio de maiorias significativas na Assembleia-Geral da ONU. Em 26 de fevereiro de 2012, duas semanas após o segundo veto ao projeto de resolução em sede de Conselho de Segurança, a Assembleia-Geral aprovou por 137 votos contra 12 (e 17 abstenções) a adoção de uma Resolução contendo grande parte do texto do projeto rejeitado no âmbito do Conselho. A Resolução da Assembleia condena as "violações generalizadas e sistemáticas dos direitos humanos pelas autoridades sírias”, apela a todos os grupos armados para que ponham fim imediato à violência e às represálias, apoia a iniciativa de paz da Liga Árabe, e reclama o apoio do Secretário-Geral (A.66/L.36, de 16 de fevereiro de 2012). Entre os Estados que votaram contra a Resolução estiveram a Rússia, a China, a Coreia do Norte, o Irão, a própria Síria, o Zimbabué e a Venezuela. Será curioso notar, tendo em vista os nossos presentes propósitos, que entre os apoiantes da Resolução estiveram alguns dos Estados - casos do Brasil, da Índia, da África do Sul e do Paquistão - que mais ruidosamente haviam criticado a intervenção da NATO na Líbia.

Volvidos alguns meses, a 3 de agosto de 2012 - um dia depois de Kofi Annan ter anunciado a decisão de se demitir do cargo de enviado conjunto para a Síria, com base na recusa das partes em honrar os compromissos 
e na incapacidade do Conselho de Segurança para assumir uma resposta eficaz -, a Assembleia-Geral adotou uma segunda Resolução sobre a situação na Síria, mais uma vez por uma larguíssima maioria de 132 votos contra 12. Esta Resolução, redigida em grande parte pelo Qatar e pela Arábia Saudita, revelar-se-ia algo mais controversa do que a primeira na medida em que lançava as críticas exclusivamente sobre as autoridades sírias, sem, por outro lado, condenar as atrocidades cometidas pelos grupos oposicionistas, problema que foi apontado principalmente pela Índia. Especialmente significativo, para o que vimos afirmando, é que a Resolução afirmava "deplorar" a não adoção de quaisquer medidas sobre a Síria por parte do Conselho de Segurança, transmitindo assim um sinal claro de que a posição do Conselho não refletia a da generalidade dos membros da ONU. A polémica em torno da falta de imparcialidade gerou um número maior de abstenções do que aquando da primeira votação (31, incluindo, desta vez, a Índia e o Paquistão), mas não se traduziu em mais votos negativos. No entanto, apesar destas reservas o Brasil e a África do Sul votaram a favor da Resolução (GA/11266, de 3 de agosto de 2012).

A disposição manifestada pela Assembleia-Geral no sentido de apoiar uma resposta mais tempestiva e decisiva para a crise na Síria e de censurar o Conselho de Segurança confere mais peso ao argumento de que não terá existido, em consequência das polémicas decorrentes da aplicação da Resolução 1973 sobre a Líbia, uma reação negativa generalizada contra a RdeP e a proteção de pessoas. Esperar-se-ia uma posição mais equívoca da parte da Assembleia-Geral se porventura a aplicação da Resolução 1973 tivesse tido repercussões negativas mais generalizadas. Ora o que sucedeu foi que a Assembleia-Geral - incluindo Estados que haviam manifestado reservas acerca da situação na Líbia - deu um claro sinal de que o veto aos três projetos de resolução do Conselho de Segurança não refletiu a atitude generalizada dos membros da ONU.

\section{Conclusão}

Aos poucos, a ONU, os Estados que a compõem e as organizações de âmbito internacional e regional têm vindo a empenhar-se cada vez mais ativamente no sentido de proteger as populações contra o genocídio e as atrocidades em massa. Tal facto indicia o surgimento de um novo regime internacional de proteção de pessoas, graças ao qual aquilo que antes era encarado como uma prática nova (o uso da força para proteger civis em contextos de manutenção da paz) passou a ser comum, e os velhos limiares (o uso da força contra Estados soberanos) foram sendo ultrapassados. Procurei demonstrar que este regime foi tornado possível 
pelos esforços feitos no sentido de eliminar o fosso existente entre os diferentes entendimentos morais, nomeadamente através da inserção dos princípios humanitários numa moldura baseada nas regras de convivência internacional vigentes. É evidente que este espaço de aproximação faz com que o regime seja menos proativo do que alguns achariam desejável, mas ao mesmo tempo confere-lhe legitimidade e, portanto, sustentabilidade a longo prazo. O que é mais, dado o Conselho de Segurança ser um órgão político, e porque poucas decisões haverá mais intrinsecamente políticas do que as que implicam o uso da força, os progressos têm sido desconexos e pouco consistentes. No entanto, não devemos deixar que as inconsistências pontuais escondam a evidência daquilo que são as claras mudanças subjacentes à prática do Conselho de Segurança da ONU.

À medida que o Conselho e outros atores se vão tornando mais ativos nesta área, assim tenderão a aumentar também as preocupações quanto à imposição e gestão do recurso à força e, com elas, as exigências de novos pesos e contrapesos. A longo prazo, estas exigências não poderão deixar de ser satisfeitas se o Conselho de Segurança da ONU quiser continuar a poder servir-se de todos os meios disponíveis para proteger as populações contra abusos da pior espécie. A simples circunstância de estarmos ainda a debater a questão desta maneira - em termos do problema de como aplicar, em situações da maior dificuldade, um princípio que é compartilhado - é a prova da distância que já foi percorrida pelo regime emergente de proteção de pessoas. Se quisermos avançar ainda mais, será necessário mais trabalho, de maneira a garantir que se protege a legitimidade quando se usa a força para proteger.

Deste modo, a próxima etapa no pensamento e na prática respeitantes à proteção das populações deverá centrar-se na melhoria das análises dos riscos emergentes, nas lições a retirar dos diversos casos abordados no presente ensaio, e no reforço dos mecanismos de responsabilização dentro do Conselho de Segurança da ONU. No seu conjunto, estes aspetos ajudarão a criar uma plataforma sólida para levar por diante a tarefa de tornar a proteção das populações contra o genocídio e as atrocidades em massa uma realidade quotidiana.

Tradução de João Paulo Moreira

Recebido a 23.02.2014

Aprovado para publicação a 24.07.2014 


\section{Referências bibliográficas}

Bellamy, Alex J. (2009), "Military Intervention", in D. Bloxham; D. Moses (orgs.), Oxford Handbook of Genocide Studies. Oxford: Oxford University Press, 597-616.

Bellamy, Alex J.; Williams, Paul D. (2010), Understanding Peacekeeping. Cambridge: Polity [2. ${ }^{a}$ edição].

Bellamy, Alex J.; Williams, Paul D. (2011), "The New Politics of Protection? Cote d'Ivoire, Libya and the Responsibility to Protect", International Affairs, 87(4), 825-850.

Bull, Hedley (1977), The Anarchical Society: A Study of Order in World Politics. London: Macmillan.

Caney, Simon (2005), Justice Beyond Borders: A Global Political Theory. Oxford: Oxford University Press.

Commission on Human Security (2003), Human Security Now. New York: Commission on Human Security.

de Waal, A.; Conley-Zilkic, B. (2006), "Reflections on How Genocidal Killings are Brought to an End", Social Science Research Council, 22 de dezembro.

Evans, Gareth (2010), The Responsibility to Protect: Ending Mass Atrocity Crimes Once and For All. Washington, DC: The Brookings Institution.

Evans, Gareth (2012), "Responding to Mass Atrocity Crimes: The Responsibility to Protect after Libya and Syria", Conferência na Central European University, Budapeste, 24 de outubro.

Frost, Mervyn (2003), “Tragedy, Ethics and International Relations”, International Relations, 17(4), 477-495.

Glanville, Luke (2011), "The Antecedents of Sovereignty as Responsibility”, European Journal of International Relations, 17(2), 233-255.

Goldberg, Mark Leon (2012), "How Libya's Success Became Syria's Failure”, UN Dispatch, 19 de janeiro.

Jackson, Robert (2000), The Global Covenant: Human Conduct in a World of States. Oxford: Oxford University Press.

Kant, Immanuel (1903), Perpetual Peace: A Philosophical Essay. Tradução de M. Campbell Smith. London: Simon Sonnenschein \& Co [ed. orig.: 1795].

Lebow, Richard Ned (2003), The Tragic Vision of Politics: Etbics, Interests and Orders. Cambridge: Cambridge University Press.

Niebuhr, Reinhold (1938), Beyond Tragedy: Essays on the Christian Interpretation of History. London: Nisbet and Co.

Morgenthau, Hans J. (1948), Politics Among Nations. New York: Alfred Knopf.

Ramsey, Paul (2002), The Just War: Force and Political Responsibility. Lanham: Rowman and Littlefield.

Reike, Ruben (2012), "Libya and the Responsibility to Protect: Lessons for the Prevention of Mass Atrocities”, St. Antony's International Review, 8(1), 122-149. 
Strauss, Ekkehard (2009), The Emperor's New Clothes? The United Nations and the Implementation of the Responsibility to Protect. Berlin: Nomos.

Teitt, Sarah (2011), “The Responsibility to Protect and China's Peacekeeping Policy", International Peacekeeping, 18(3), 298-312.

Tesón, Fernando R. (2003), “The Liberal Case for Humanitarian Intervention”, in J. L. Holzgrefe; Robert O. Keohane (orgs.), Humanitarian Intervention: Ethical, Legal and Political Dilemmas. Cambridge: Cambridge University Press, 93-129. Walzer, Michael (1977), Just and Unjust Wars: A Moral Argument with Historical Illustrations. New York: Basic Books.

Walzer, Michael (1983), Spheres of Justice: A Defence of Pluralism and Equality. Oxford: Basil Blackwood.

Walzer, Michael (1994), Thick and Thin: Moral Argument at Home and Abroad. Notre Dame, IN: University of Notre Dame Press. 
